\title{
PATTERN RECOGNITION OF AIR PHOTOGRAPHS FOR ESTIMATION OF SNOW RESERVES
}

\author{
by
}

\author{
W. Good and J. Martinec
}

(Swiss Federal Institute for Snow and Avalanche Research, 7260 Weissfluhjoch/Davos, Switzerland)

\begin{abstract}
A certain snow-covered area determined from air photographs in different years can contain different volumes of snow. The pattern recognition of snow fields reveals whether the snow reserves are relatively high or low for the given snow coverage. It also signals a short term increase of the snow-covered area by summer snowfall.
\end{abstract}

\section{INTRODUCTION}

A typical feature of the seasonal snow cover in the mountains is its diminishing areal extent during the melt season. This phenomenon greatly reduces the risk of floods from snow melt in mountainous basins. Since the advent of remote sensing, the snow cover can be efficiently monitored. Efforts are in progress to improve the methods of snow-cover mapping with the use of orthophotographs from aircraft and of satellite data. This paper deals with estimating the snow reserves in terms of the water equivalent from this two-dimensional information by the pattern recognition of structured snowfields.

\section{SNOW-COVERED AREA WITH REGARD TO SNOW ACCUMULATION}

The snow-covered area had already been used as an index of the snow accumulation in terms of water equivalent 50 years ago (Potts 1937). The subsequent run-off volumes in various years deviated sometimes from forecasts based on such relations. These discrepancies were at first attributed to the varying summer precipitation in the respective years. Another source of error was the crude method of estimating the snow-covered area just from panoramic terrestrial photographs of a mountain range.

In the following decades, the accuracy and efficiency of snow-cover mapping were improved by terrestrial observations (Garstka and others 1958), air photographs and in particular by remote sensing from satellites. However, the old assumption linking the snow-covered area with the water volume stored in the snow cover remained (Ødegaard and others 1980; Shafer and Leaf 1980).

At the same time, detailed measurements in wellequipped representative basins (Martinec 1980) have shown that there is no unequivocal relation between the areal extent of the seasonal snow cover in a mountain basin and the snow accumulation in terms of water equivalent. As is explained elsewhere (Hall and Martinec 1985) the gradually decreasing area of the snow cover reflects not only the initial snow accumulation, but also climatic conditions during the snow-melt season of the given year. In order to overcome this problem, a method of evaluating the snow accumulation from a sequence of satellite or aircraft images of the snow cover has been developed (Martinec and Rango 1987). In this paper, the pattern of snow-cover boundaries is used to estimate whether a certain areal extent of the seasonal snow cover has a high or low snow-water equivalent.

\section{IMAGE ANALYSIS AND PATTERN RECOGNITION Working hypothesis}

Ideally, a horizontal, two-dimensional surface is either covered with snow or it is void. In reality the transition time between these two states during ablation is short and becomes longer as the roughness of the surface increases. In mountainous areas where the topography is very complicated, the delay is even more accentuated because of the elevation range and temperature lapse rate.

During the process of disintegration, a contiguous snow cover successfully reveals details from the subjacent terrain. A given area of snow represents smaller amounts of water if more topographic details are visible (Good 1983). These signatures seem to be typical and reproducible for given areas and describe not only a state of the snow cover during melting, but they also represent the quantity of snow. In the present paper we try to quantify this hypothesis.

\section{Methods used}

It soon became evident that the resolution of the images used was one of the most critical conditions in defining the relevant structures. The resolution that is necessary to reveal the required topographic details, is of the order of a few metres.

Resolution, however, is not of itself sufficient; it has to be considered in relation to the areal extent of the test site under investigation (e.g. Dischma Valley, Swiss Alps, European Alps), and to the point resolution of the image analysis system. For the Dischma Valley, air photographs appear to be adequate. We work with a HAMAMATSU slow-scan video camera with a typical point resolution of $512 \times 512$ pixels (maximum $1024 \times 1024$ pixels) corresponding to a pixel size of $11.2 \mathrm{~m}$. If the relevant topographic structures are finer or the resolution due to the pixel size is too coarse, no significant analysis is possible. Below this limit the patches without snow have only the effect of reducing the albedo. The snow appears to be slightly darker which influences the selection of the discriminant level. This does not, however, reveal the required signatures. These limitations are found in photographs which represent typical new snow situations such as that on 29 August 1985, when about $85 \%$ of the test area was covered with new snow. In spite of its large extent, this short-lived snow cover contained on the average only several centimetres of water equivalent. We tried various methods to quantify the signatures (structures) and to correlate the resulting parameters with the quantity of water stored in the corresponding snow cover.

\section{Data set}

Orthophotographs $(1: 50$ 000) from the Dischma Valley (flights between 1972 and 1981) were separated into an upper and a lower part in order to improve the point resolution and also to increase the number of samples (22). The upper part with an area of $21.5 \mathrm{~km}^{2}$, ranging from 1900 to $3150 \mathrm{~m}$ a.s.l., is examined in this study. Care 
TABLE I. POINT COUNT PARAMETERS

SYMBOL

RHO

$\mathrm{P}_{\mathrm{S}}$

$\mathrm{P}_{\mathrm{v}}$

INS

DMI

FRE

$\mathrm{F}_{1}$

$\mathrm{F}_{2}$
NAME

point density (mean)

fraction of snow(s)-pixels

fraction of void(v)-pixels

intersections (mean)

snow intercept length (mean)

void intercept length (mean)

form factor 1 (mean)

form factor 2 (mean)

\section{DEFINITION}

$\mathrm{RHO}=\mathrm{P}_{\mathrm{S}} /\left(\mathrm{P}_{\mathrm{S}}+\mathrm{P}_{\mathrm{v}}\right)$

transitions $\mathrm{s} / \mathrm{v}$ and $\mathrm{v} / \mathrm{s}$

distance between $\mathrm{v} / \mathrm{s}$ and $\mathrm{s} / \mathrm{v}$

distance between $s / v$ and $v / s$

$\mathrm{F}_{1}=\mathrm{INS} / 2 \times \mathrm{FRE}$

$\mathrm{F}_{2}=1-\mathrm{DMI} / \mathrm{FRE}$

Histograms, mean (X..), variance (XSD), minimum (XMI) and maximum (XMA) are available per parameter $[\mathrm{X}$ is for $\mathrm{R}, \mathrm{I}, \mathrm{D}, \mathrm{F}]$

must be taken to avoid those samples where new snow would cause a bias in the evaluation.

\section{A/D conversion}

The 22 samples were digitized with the slow-scan video camera linked to a PDP $11 / 44$. The grey level of each pixel is evaluated in an 8 bit scale. The 262144 intensities of each picture are stored on magnetic tapes. The conversion of one frame $(512 \times 512$ pixel) takes roughly $90 \mathrm{sec}$.

\section{Preprocessing}

The only subjective step, and perhaps the most important one in the processing is the selection of the adequate limit where the intensity of a pixel signal is either a snow-covered or a snow-free area. In an ideal picture a single discriminant level may exist, but even here it has to be selected so that the original and the binary picture are as similar as possible. In real pictures, a dramatic amount of information is lost if one discriminant level only is used to split the pixels into a snow/no-snow binary picture. The reason is the slow and continuous variation of intensities over the whole picture and the local differences due to changing lighting conditions, snow quality, vegetation etc.

Local image operations of the edge-detection type were applied. The enhancement algorithm checks every pixel against its four nearest neighbours. A transition white-black is initiated if the pixel in the centre is slightly darker, within a discrimination band, than the surrounding ones, or if, in an absolute sense, it is darker than the lower limit of the discrimination band. In the enhanced pictures many of the required details reappear (Fig.1). The reproducibility of the areal extent of the snow cover could be kept within $\pm 6 \%$.

\section{Parametrization}

A set of pattern recognition parameters and a set of simple point count parameters were computed after image enhancement. The first group normally represents the geometry of the structures in a more comprehensive way. Because of the small extent of many structural details, the pattern recognition tended to reflect the coordinate frame rather than the structures. Therefore we worked with the less critical set of point count parameters.

\section{NUMERICAL ANALYSIS}

The extent of the snow cover in the analysed situations represented $57 \%$ and $93 \%$ respectively of the total area. We expect certain parameters describing the snow-free patches (topography) to be the important ones. A factorial analysis (Cooley and Lohnes 1973; SSP, ISPAHAN) yields an orthogonal coordinate frame where the axes (principal components) are linear combinations of the initial parameters. Axis number one, belonging to the first (largest) eigenvalue, is selected in such a way that the total

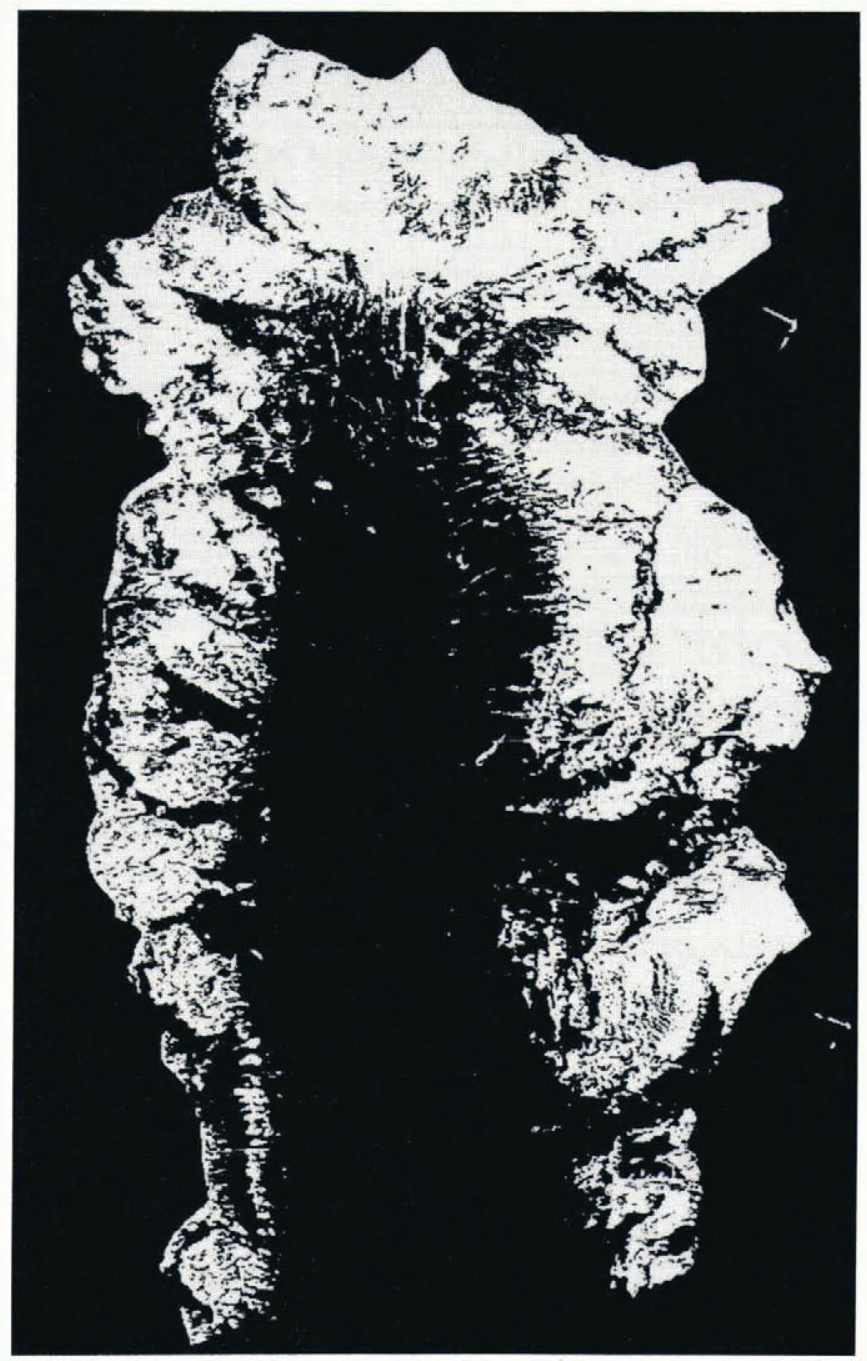

Fig.1. Digitally enhanced orthophotograph of Dischma Valley. Pixel size is $11.2 \mathrm{~m}$ (situation from 5 July 1974).

dispersion of the points is maximized. The second one, associated with the second largest eigenvalue and all the following ones are mutually orthogonal.

Comparing the measured quantities of water from the respective snow covers with the linear combinations of parameters, we found reasonable descriptions of the two situations. 


\section{Models}

The first principal component contains the information about the areal extent of the snow cover (RHO, RSD RMA). (Table I). The following combination of number of intersections and distance between snow patches relates to some extent to the run-off volumes of water (ranging from 4 to $16 \times 10^{6} \mathrm{~m}^{3}$ ) from the snow cover (Fig.2).

$\mathrm{PRCO} 2=0.4 \times \mathrm{INS}+0.4 \times \mathrm{INS} / \mathrm{FRE}-0.38 \times \mathrm{FRE}+\ldots$

The respective water volumes stored in snow are represented by the measured discharge volumes from the test area. The snow reserves are slightly higher in view of the run-off losses and problems in separating the snow melt and rain component, as explained in the next section. The linear relationship between the water volume and PRCO2 plotted in Fig.2 has a coefficient of determination of $\mathrm{R}^{2}=0.89$. The differences in discharge volumes corresponding to approximately equal snow-covered areas, however, are significant. In the group of $56.63 \% \pm 3.63 \%$ snow coverage, a discharge of $3.9 \times 10^{6} \mathrm{~m}^{3}$ corresponds to the individual with $58.2 \%$ of snow, whereas $6.8 \times 10^{6} \mathrm{~m}^{3}$ corresponds to the individual with $51.9 \%$ of snow. This contradiction to the areal extent can only be resolved with another combination of parameters describing the variability of geometric features of the snow cover: minimum of snow patch diameters and of covered area and difference of standard deviations of diameters of patches of snow and void. This finer discrimination is accomplished by plotting $Q$ versus PRCO5 (see Fig.3).

$\mathrm{PRCO} 5=0.58 \times \mathrm{DMI}+0.47 \times \mathrm{RMI}+0.31 \times \mathrm{FSD}-0.32$ $\times$ DSD + ...

The regression coefficient is 0.987 . The same model is not directly applicable to the $93 \%$ group; apparently the $7 \%$ of the area that is snow-free has not enough structural details.

\section{COMPARISON OF ESTIMATED SNOW RESERVES WITH} MEASUREMENTS

The years 1972, 1974, 1976, and 1978 have been selected to show that an approximately equal snow-covered area in the alpine basin Dischma can contain either a high or a low snow volume. The years 1972 and 1976 are evaluated in the previous section as "low", and the years 1974 and 1978 as "high". This is in agreement with the direct point measurements at testsite, $2540 \mathrm{~m}$ a.s.1., which can be related to the examined test section of the Dischma basin.

The estimated snow reserves can also be compared with the resulting run-off volumes. To this effect, the run-off from the test area of $21.5 \mathrm{~km}^{2}$ was derived from a recording water gauging station situated up-stream (catchment area $12.5 \mathrm{~km}^{2}$ ) and from another recording water gauging station at the outlet of the Dischma basin (representing $43.3 \mathrm{~km}^{2}$ ). Data are summarized in Table II, where $S$ is the snow-covered area evaluated from an aircraft orthophotograph on the given date $(100 \times$ RHO $)$, $\mathrm{H}_{\mathrm{w}}$ is the point water equivalent of the snow cover measured at $F$ Weissfluhjoch. $R$ is the run-off depth from the test area of $21.5 \mathrm{~km}^{2}$ and $\mathrm{P} \times 0.7$ is precipitation during run-off period multiplied by a run-off coefficient.

Since there is no clear-cut time limit of snow melt run-off, the daily run-off volumes were added in each year until a total of 150 degree-days was reached from temperature measurements at Weissfluhjoch, $2693 \mathrm{~m}$ a.s.l. By subtracting the run-off from precipitation from the total run-off, run-off depths related to the initial snow reserves are obtained.

The years 1974, 1975, 1979, and 1980 show again a similar snow coverage at certain dates, considerably higher than in the previous example. In this group, however, it was not possible to discriminate between the respective years by the axis PRCO5. As shown in Table III, the snow reserves are very similar in $1974,1975,1980$ and distinctly lower in 1979. Also, as already mentioned, the snow-free

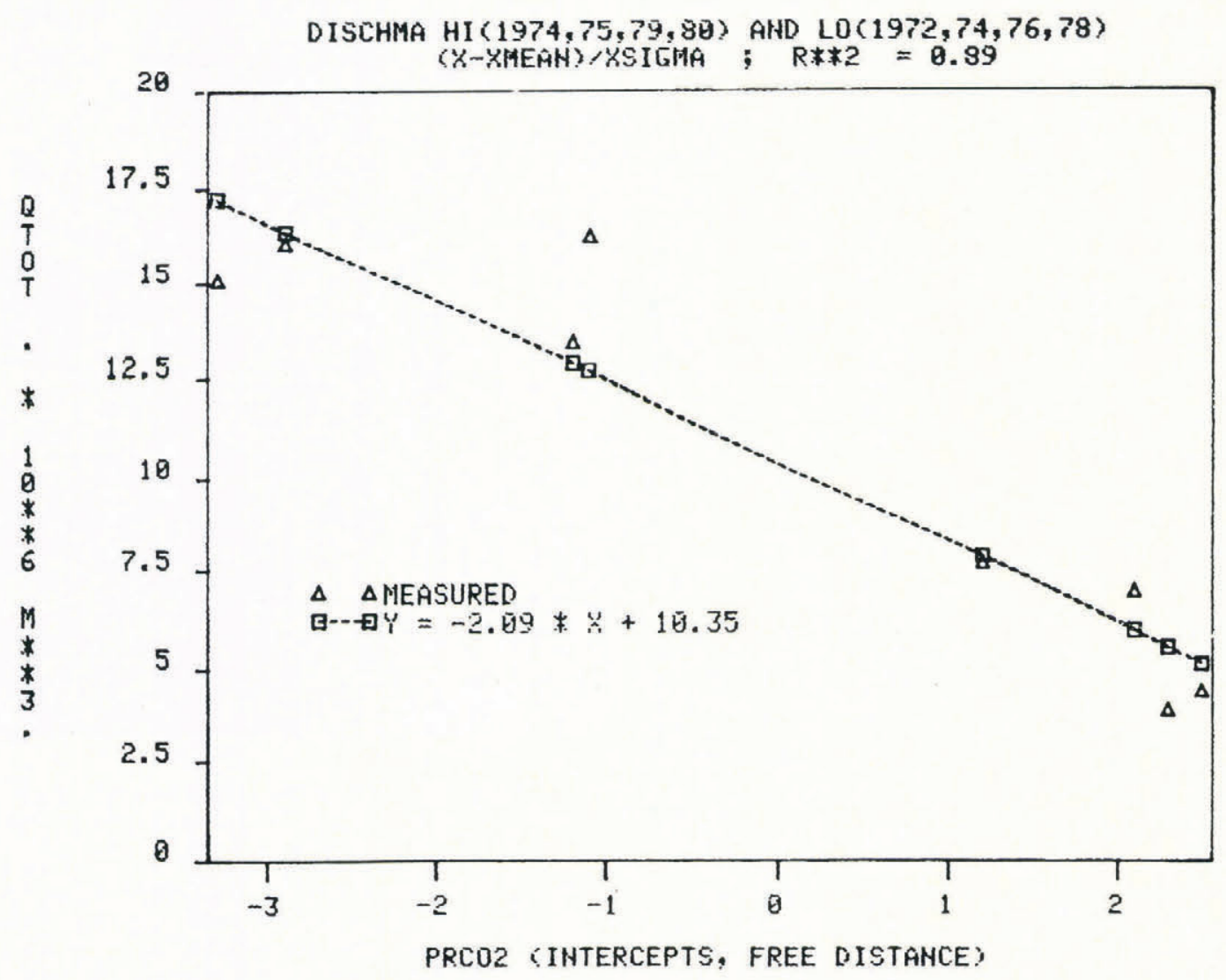

Fig.2. Run-off $Q$ as a function of the number of snow/void and void/snow transitions and of the free distance (PRCO2). 


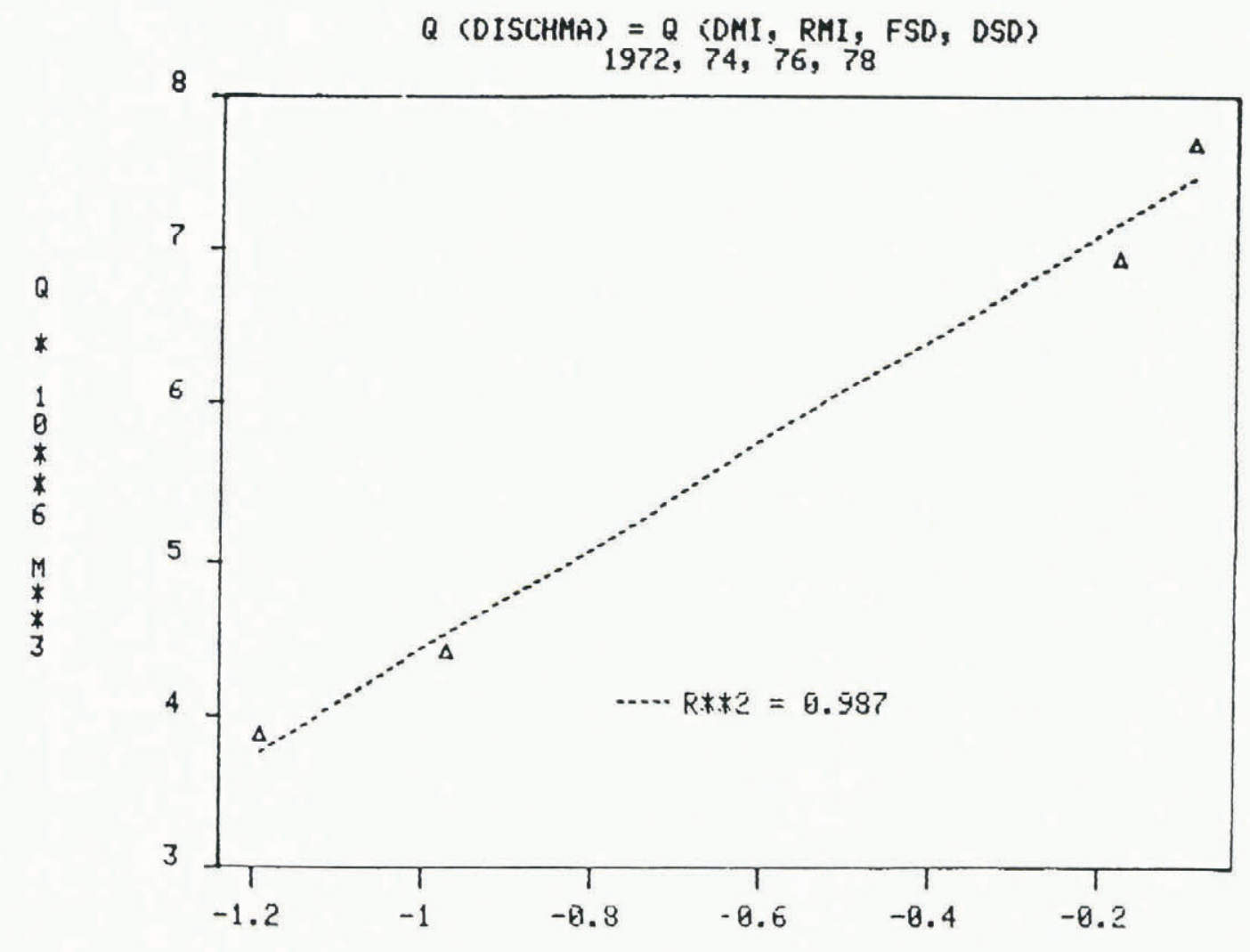

PRCO5 (DII , RMI, FSD, DSD)

Fig.3. Run-off Q as a function of PRCO5. For a similar extent of the snow cover, two typical situations ("high", "low") can be resolved.

TABLE II. MEASURED WATER EQUIVALENTS OF SNOW AND RUN-OFF VOLUMES FOR COMPARISON WITH THE ESTIMATED SNOW RESERVES
DATE
$\mathrm{S}$
$\%$$\quad \mathrm{~F} \quad \mathrm{H}_{\mathrm{w}}^{\mathrm{cm}}$
$\mathrm{R}$
$\mathrm{cm}$
$P \times 0.7$
$\mathrm{R}-\mathrm{P} \times 0.7$
Snow reserves

\begin{tabular}{rrrrrrr}
\hline 21 June 1972 & 56 & 33.7 & 30.7 & 10.3 & 20.4 & low \\
8 June 1976 & 58 & 34.8 & 20.5 & 2.4 & 18.1 & low \\
5 July 1974 & 60 & 70.4 & 45.5 & 9.7 & 35.8 & high \\
17 July 1978 & 52 & 62.4 & 41.0 & 8.7 & 32.3 & high
\end{tabular}

TABLE III. MEASURED WATER EQUIVALENTS AND RUN-OFF VOLUMES FOR COMPARISON WITH THE ESTIMATED SNOW RESERVES

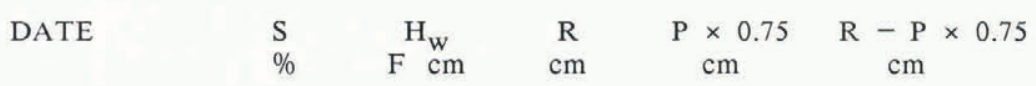

$\begin{array}{rrrrrr}\text { 16 May 1974 } & 96 & 101.6 & 100.4 & 30.2 & 70.2 \\ \text { 20 May 1975 } & 94 & 117.1 & 102.1 & 26.4 & 75.7 \\ \text { 5 June 1980 } & 92 & 111.7 & 97.1 & 22.3 & 74.8 \\ \text { 22 May 1979 } & 93 & 95.7 & 79.6 & 17.2 & 62.4\end{array}$


area is too small to provide enough details for the analysis. The symbols are the same as in Table II. The run-off coefficient for precipitation was increased slightly to 0.75 because the snow-covered area is larger than in the previous case so that smaller losses are indicated. Since the run-off period starts at an earlier stage of the snow melt season than in the previous comparison, the number of degree-days measured at Weissfluhjoch was increased to 225 to obtain the respective final dates in each year. The runoff depths are again computed for the periods thus defined and run-off related to precipitation is subtracted in order to obtain values referring to the estimated snow reserves.

\section{CONCLUSION}

By the above method it is possible to recognize whether a certain areal extent $(40-70 \%)$ of the seasonal snow cover contains a high or a low volume of snow. In this study the required spatial resolution of snow cover images was of the order of $10 \mathrm{~m}$. If new snow is superimposed on the seasonal snow cover during the snow melt season, the fine structure of snow fields and the complex boundaries prevent the snow-covered and snowfree patches from being recognized. The identification of such scenes helps to avoid errors in periodical snow-cover mapping.

\section{REFERENCES}

Cooley W W, Lohnes R R 1973 Multivariate data analysis. New York, John Wiley and Sons

Garstka W U, Love L D, Goodell B C, Bertle F A 1958 Factors affecting snowmelt and streamflow. Washington, DC, Government Printing Office

Gelsema E S (ed) 1981 ISPAHAN users' manual. Amsterdam, Free University. Department of Medical Informatics

Good W 1983 Estimation par des méthodes de traitement d'images de la quantité d'eau stockée dans un bassin versant. Weissfluhjoch/Davos, Institut Féderal pour l'Etude de la Neige et des Avalanches (Rapport Interne 609)

Hall D K, Martinec J 1985 Remote sensing of ice and snow. London and New York, Chapman and Hall

IBM Corporation 1968 System /360 Scientific Subroutine Package, version III. Programmers' manual. New York, IBM Corporation

Martinec J 1980 Limitations in hydrological interpretation of the snow coverage. Nordic Hydrology 11(5): 209-220

Martinec J, Rango A 1987 Interpretation and utilization of areal snow-cover data from satellites. Annals of Glaciology 9: $166-169$

Ødegaard H A, Andersen T, Østrem G 1980 Application of satellite data for snow mapping in Norway. In Rango A, Peterson R (eds) Operational Applications of Satellite Snowcover Observations. Proceedings ... Nevada ... 1979. Greenbelt, MD, NASA: 93-106 (NASA Conference Publication 2116)

Shafer B A, Leaf C F 1980 Landsat derived snowcover as an input variable for snowmelt runoff forecasting in south central Colorado. In Rango $\mathrm{A}$, Peterson $\mathrm{R}$ (eds) Operational Applications of Satellite Snowcover Observations. Proceedings of a final workshop ... held at Sparks, Nevada April 16-17, 1979. Greenbelt, MD, NASA: 151-169 (NASA Conference Publication 2116) 